\title{
Relative Diffusion as Related to Quasi-Periodic Current Structures
}

\author{
B. C. KenneY $Y^{1}$ and IAN S. F. Jones ${ }^{2}$ \\ The University of Waterloo, Ontario, Canada \\ (Manuscript received 11 May 1970, in revised form 26 March 1971)
}

\begin{abstract}
Experiments were performed in Lake Huron in which the relative diffusion of a dye plume and the lateral component of turbulent velocity were measured simultaneously. The standard deviation of the plume width varied in the same manner as the lateral turbulent intensity for cases of "regular" diffusion, although the precise relationship could not be established because Eulerian, rather than Lagrangian, time scales of the current fluctuations were measured.

Rapid vertical diffusion was associated with horizontal striations in the plume, with a quasi-periodic structure being observed simultaneously in the lake current. These striations were always aligned with the wind and rapidly followed shifts in the wind direction. It appears that these quasi-periodic current structures ensure "accelerated diffusion" when there is a variation in the direction of the current with depth. Since there is a strong association among the surface wind, the striations and current skewness, it is postulated that the surface wind plays a significant role in diffusion processes in the top few meters of the lake.
\end{abstract}

\section{Introduction}

Diffusion studies have been carried out in Lake Huron near Baie du Doré for a number of years and many of the physical processes involved in diffusion have been described (e.g., Csanady, 1963). Typical values of lateral diffusivity have been determined from many experiments but there are large variations from these average values of diffusivity on a day-to-day basis. This was the aspect of the dispersal process with which we were concerned in the summer of 1967. In an attempt to relate these variations to the fluctuating currents, the wind and the current ( $2 \mathrm{~m}$ from the interface) were recorded continuously while a dye plume was generated nearby.

The dispersal of effluents is dominated, over a long period, by the mean current in the lake which determines the direction in which the dye plume flows. It is clear that as the mean current changes direction, the dye plume swings through a large angular segment, thus tending to produce a low average concentration at a fixed point. In Lake Huron at a depth of $2 \mathrm{~m}$ a large degree of correlation was found (Jones, 1968) between the current direction and the local wind direction $18 \mathrm{hr}$ earlier, suggesting that the wind is very important in the long-time dispersal process.

For a given direction of the dye plume axis, the rate of diffusion perpendicular to this direction is controlled by the turbulence of the environmental fluid. The studies reported here were undertaken to help elucidate the connection between the diffusion and the statistics associated with the turbulence of the lake current.

\footnotetext{
${ }^{1}$ Present affiliation: Canada Center for Inland Waters, Burlington, Ontario.

2Present affiliation: Boeing Scientific Research Iaboratories, Seattle, Wash.
}

Relative diffusion in the surface layers of the lake has been broken into the following two broad categories based on concentration measurements (Csanady, 1966): 1) "regular diffusion" when the current direction is uniform in depth, and 2) "accelerated diffusion" when the diffusion rate is enhanced by a mean current skewed in depth. ${ }^{3}$ Accelerated diffusion in oceans has been considered in a similar manner by Pritchard $e t$ al. (1966).

In a study of the meandering of the center of mass of dye plumes (Kenney, 1967), two general classifications were defined based on the gross diffusion characteristics which may be observed form aerial photographs. The first class of plume has finite length of the order of $1000 \mathrm{~m}$ and is strongly striated. The second class has a laminar-like appearance and extends an order of magnitude farther downstream than the striated type. An attempt will be made here to integrate these gross characteristics observed from the air with measurements made on the lake's surface.

\section{Experimental procedure}

The experiments were carried out in approximately $20 \mathrm{~m}$ of water some $2000 \mathrm{~m}$ from the lake edge. The proximity of the shore constrains the bulk of the fluid to flow in a northeast or southwest direction and indeed current records confirm this trend (Jones, 1968). The distance from the shore was sufficient, however, to allow at least the top few centimeters of the water to follow closely the surface wind to the extent that on a number of occasions small traces of dye introduced at the surface of the lake were observed moving perpendicular to the shore.

${ }^{3}$ Skewed in depth implies a change of direction of the current with depth (regardless of speed). 
Plumes of marked fluid were formed by pumping rhodamine BNS from a catamaran securely anchored in three directions at the position shown in Fig. 1. The dye was released $2 \mathrm{~m}$ below the surface through $6.4-\mathrm{mm}$ tubing arranged so that the point of release was as close as possible to the center of buoyancy of the boat in order to minimize disturbances of the source. Rhodamine is a good tracer because it is relatively inexpensive, appears red from the air, can be detected in low concentrations because it fluoresces when excited with ultraviolet light, and is stable in lake water (having a half life of $\sim 60 \mathrm{hr}$ in sunlight).

The plume concentration was sampled from a $10 \mathrm{~m}$ catamaran on which were mounted two Turner continuous-flow fluorometers, strip chart recorders, and the appropriate power supplies. The sample was continuously withdrawn through a streamlined boom, hinged between the hulls so that it could be lowered to different depths (Fig. 2).

The current speed and direction were sensed by a Hydro products meter mounted on a fixed tower that had been installed in the position shown in Fig. 1. The current sensor was mounted on a winch so that the profiles in depth could be obtained. The current speed and direction were recorded on an analog chart via a Mosely pen recorder and later reduced to digital form

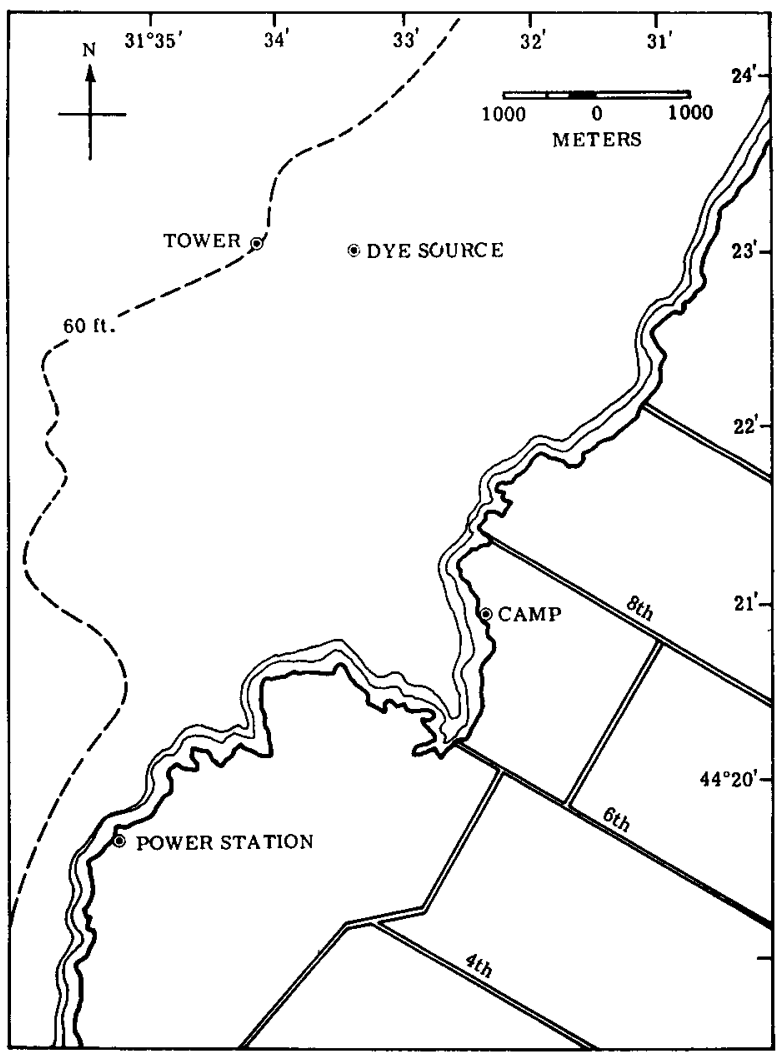

FIG. 1. Map of Lake Huron, near Baie du Doré.

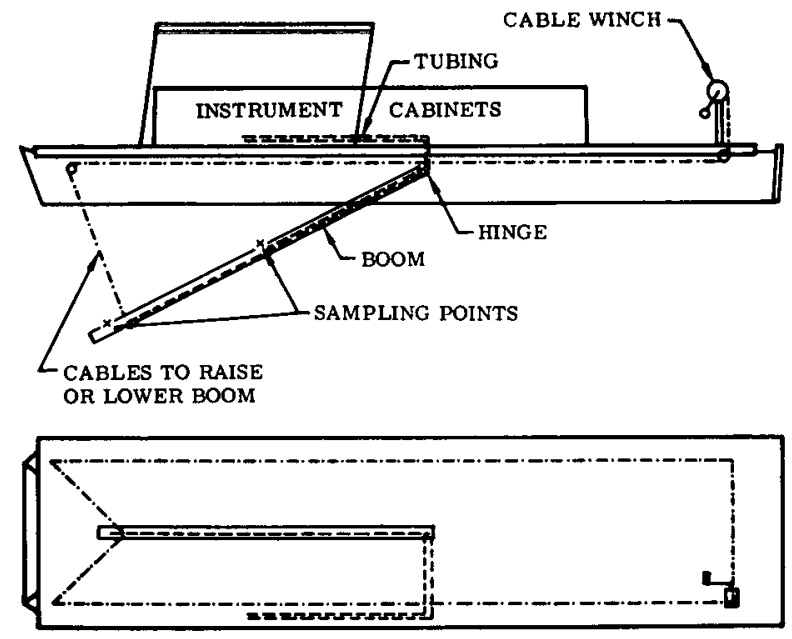

FIG. 2. Schematic of catamaran with sampling boom.

by an $x, y$ chart reading device developed by Dr. A. M. Hale of the University of Waterloo.

The aerial photographs were taken from a Cessna 172 with the aid of a Fairchild F56 camera. The contrast between the dye plume and its surroundings was heightened by using a Wratten 12 filter to reduce the sensitivity of the photographs to the blue end of the spectrum.

\section{Experimental results}

Useful data for the purpose of this paper were collected on three successive days in the latter part of August 1967. In order to extend the base for discussion, a close parallel will be drawn between these three experiments and those conducted by Kenney (1967) during late August and early September 1966. In both years the lake was isothermal in the upper $10 \mathrm{~m}$. The wind velocity was of the order of $10 \mathrm{kt}$ for all experiments under consideration. The only noteworthy environmental difference between the two years was the visibility which was poorer in 1967 .

The primary difference in the experiments of the two years was the location of the dye source. In 1967 it was placed at a depth of $2 \mathrm{~m}$ rather than at the surface. It may be seen in Fig. 3 that this change did not materially affect the gross plume characteristics as viewed in aerial photographs for either the striated (Fig. 3a) or the laminar-like plumes (Fig. 3b)

A summary of observations made on the three days of the 1967 experiment is presented in Figs. 4-6. Each of these figures shows a plume photograph in correct relative orientation to current and wind vector diagrams. Also shown are sample records of current speed and direction at $2 \mathrm{~m}$ depth, water level, temperature vs depth, mean current vs depth, and a sample plot of dye concentration across the plume. Important observations relevant to the discussion which follows are summarized below. 

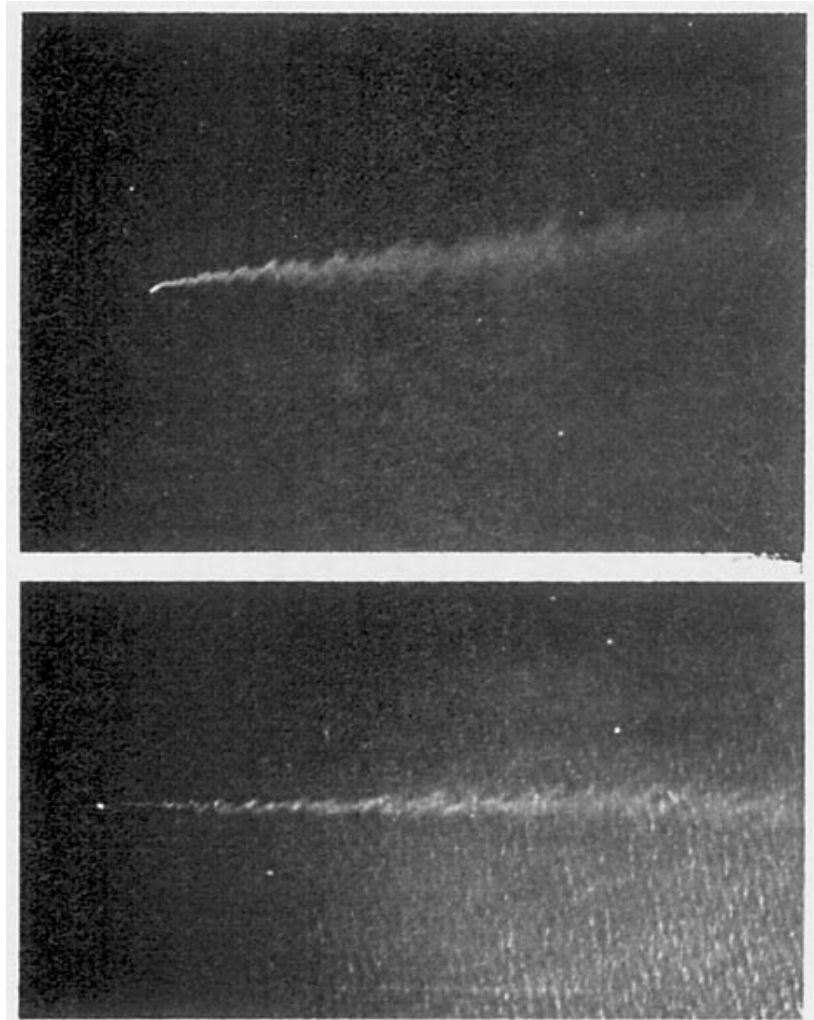

FIg. 3a. A comparison between a striated plume formed by releasing dye at the surface and at $2 \mathrm{~m}$ below the surface: top, surface release on 31 September 1966; bottom, $2 \mathrm{~m}$ release on 23 September 1967.

\section{a. 23 August 1967}

The plume showed strong striations with a spacing of $\sim 10 \mathrm{~m}$. Striations are a common feature in dye plumes and have been observed in the ocean (e.g., Icheye, 196 $i$ ), as well as in the lakes. The plume reached a steady length of the order of $1000 \mathrm{~m}$. The current velocity records at $2 \mathrm{~m}$ (both speed and direction) have quasiperiodic fluctuations with a frequency of about 1 cycle $\mathrm{min}^{-1}$. This periodicity is reflected in a peak in the frequency spectra of this record, which was presented in Fig. 2 of Jones and Kenney (1971). The current direction was uniform in depth from 2 to $10 \mathrm{~m}$ at $230 \pm 5^{\circ}$, and the striations were aligned with the wind which was blowing from the north.

\section{b. 27 Augusl 1967}

The plume was laminar-like in appearance with no visible striations, continued to grow in length throughout the experiment, and extended to more than $10,000 \mathrm{~m}$ when aerial photography was terminated. The current direction was skewed in depth such that it showed a counterclockwise variation of $10^{\circ}$ per meter at a depth of $2 \mathrm{~m}$.

\section{c. 25 August 1967}

The aerial photographs were taken at a considerably lower altitude than on the preceding days and the greater detail is evident in Fig. 6. The visibility was extremely poor on this day and as a result the aerial survey was prematurely terminated. The plume appears divided into two segments, both strongly striated. The segment near the surface had the striations aligned with the wind, while striations in the deeper segments were perpendicular to the plume axis. The current speed record at $2 \mathrm{~m}$ showed some periodicity, again of approximately 1 cycle min $^{-1}$. Below $2 \mathrm{~m}$ the current direction was uniform with time and depth, but since there was a large angle between the surface wind and this current, one can conclude that a large current shear existed in the tcp $2 \mathrm{~m}$. Kenney (1967) had proposed that plumes of this appearance were skewed and the concentration profiles on this day confirm (as did earlier profiles of some similar plumes taken in July) that this type of plume was indeed skewed in depth.

\section{Plume width}

Unlike previous years, the standard deviation of the concentration distribution about the plume's center of mass was calculated from fluorometer records. The output of the fluorometer which was recorded on a strip chart was reduced to approximately 100 digital readings
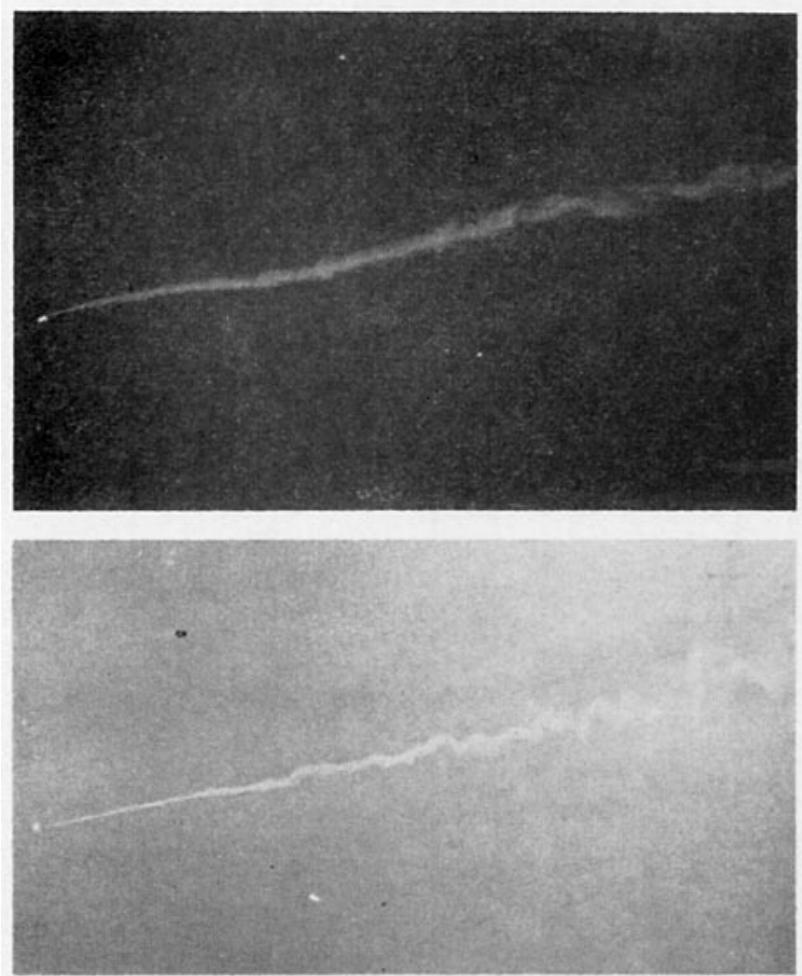

Fig. 3b. Same as Fig. 3a except for a laminar-like plume: top surface release, 27 September 1966; bottom, $2 \mathrm{~m}$ release on 24 August $196 \%$. 


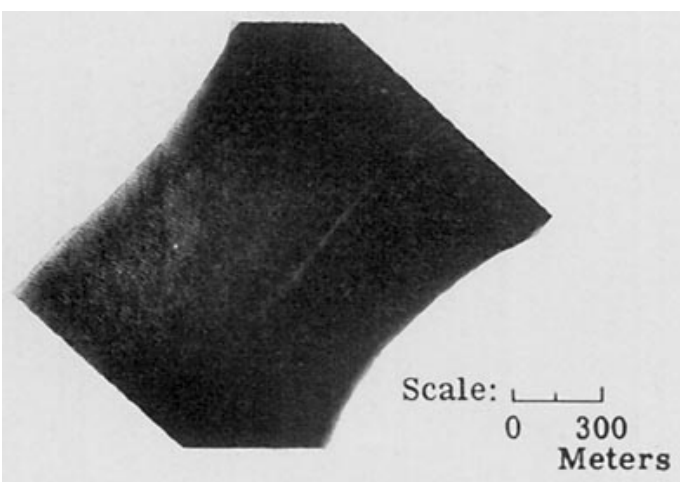

Current Speed
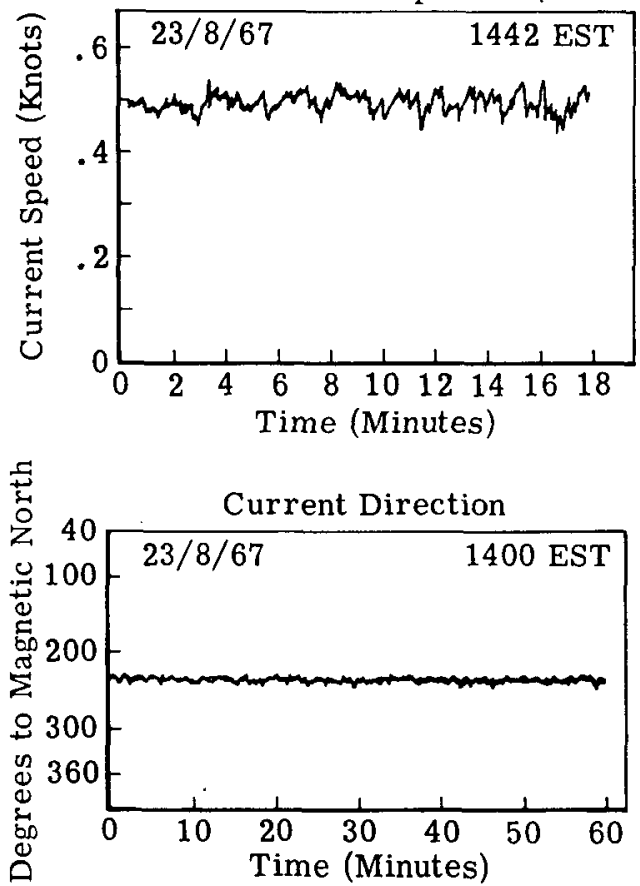

Current Profile

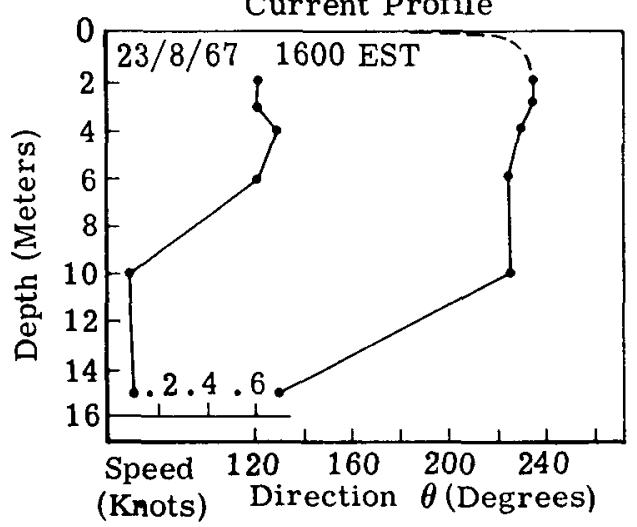

Wind Direction

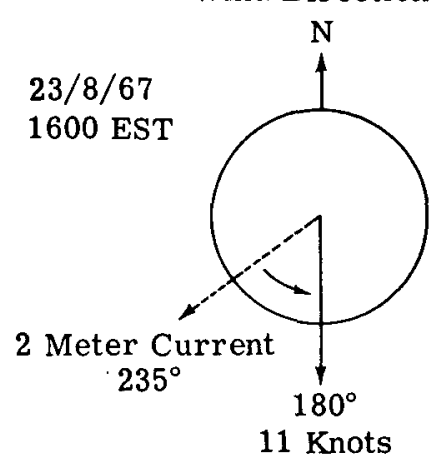

Temperature Profile
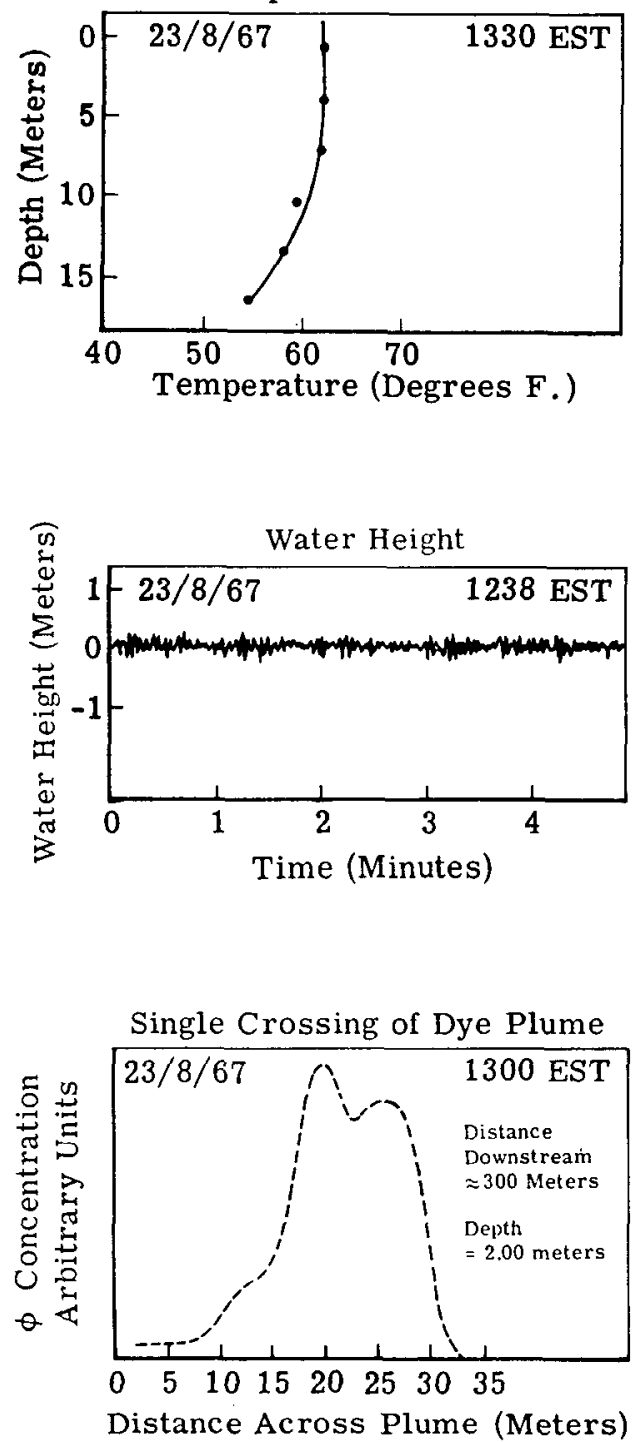

FIG. 4. Collected data for diffusion experiment on 23 September 1967. 

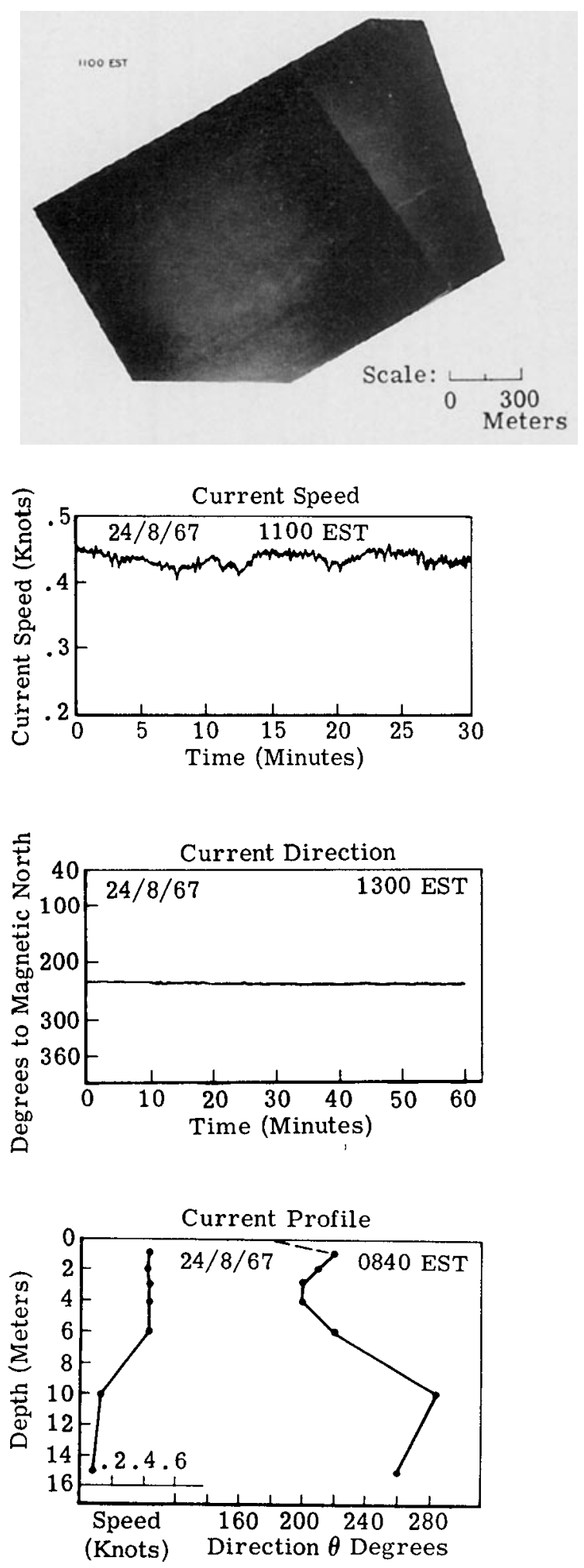

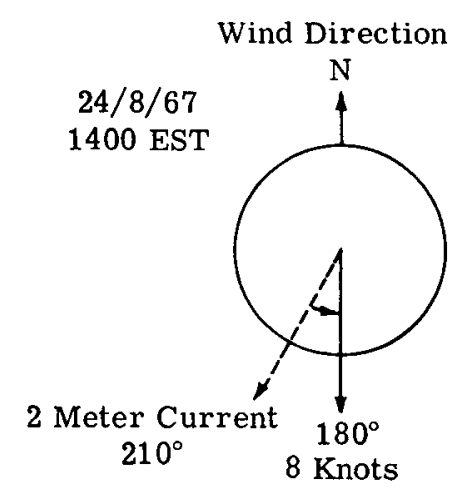

Temperature Profile
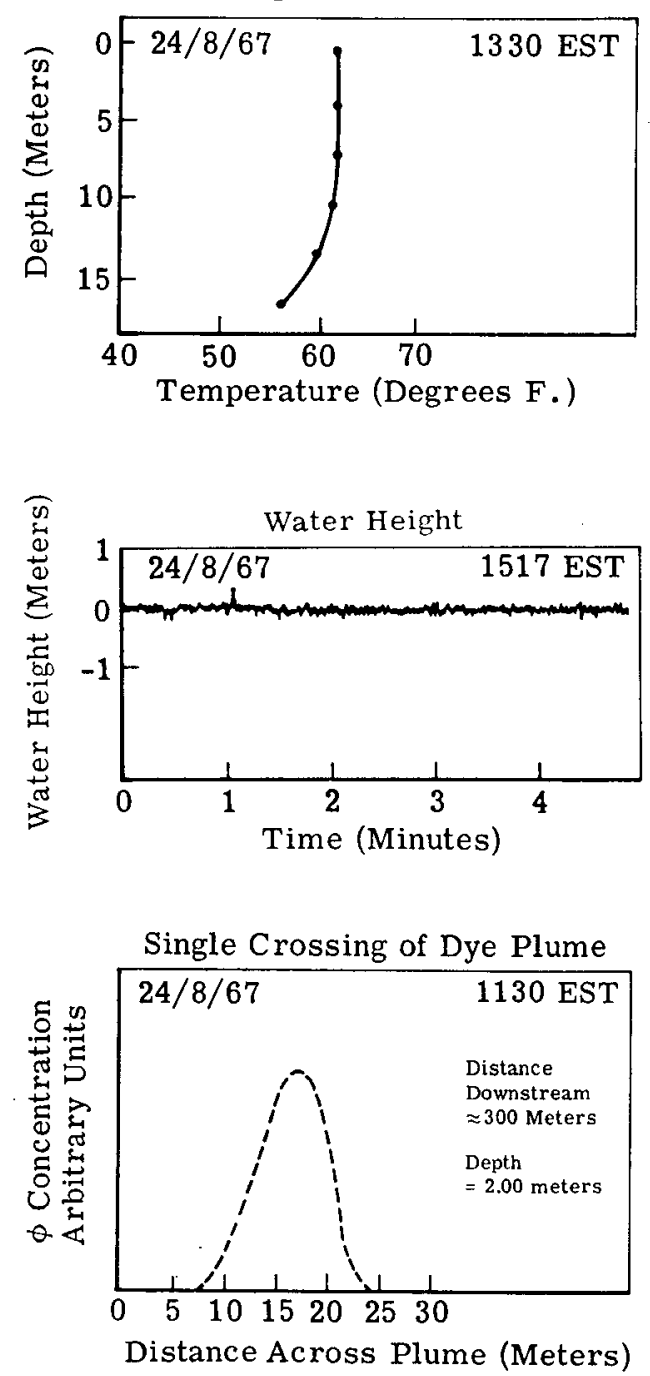

FiG. 5. Collected data for diffusion experiment on 24 September 1967. 

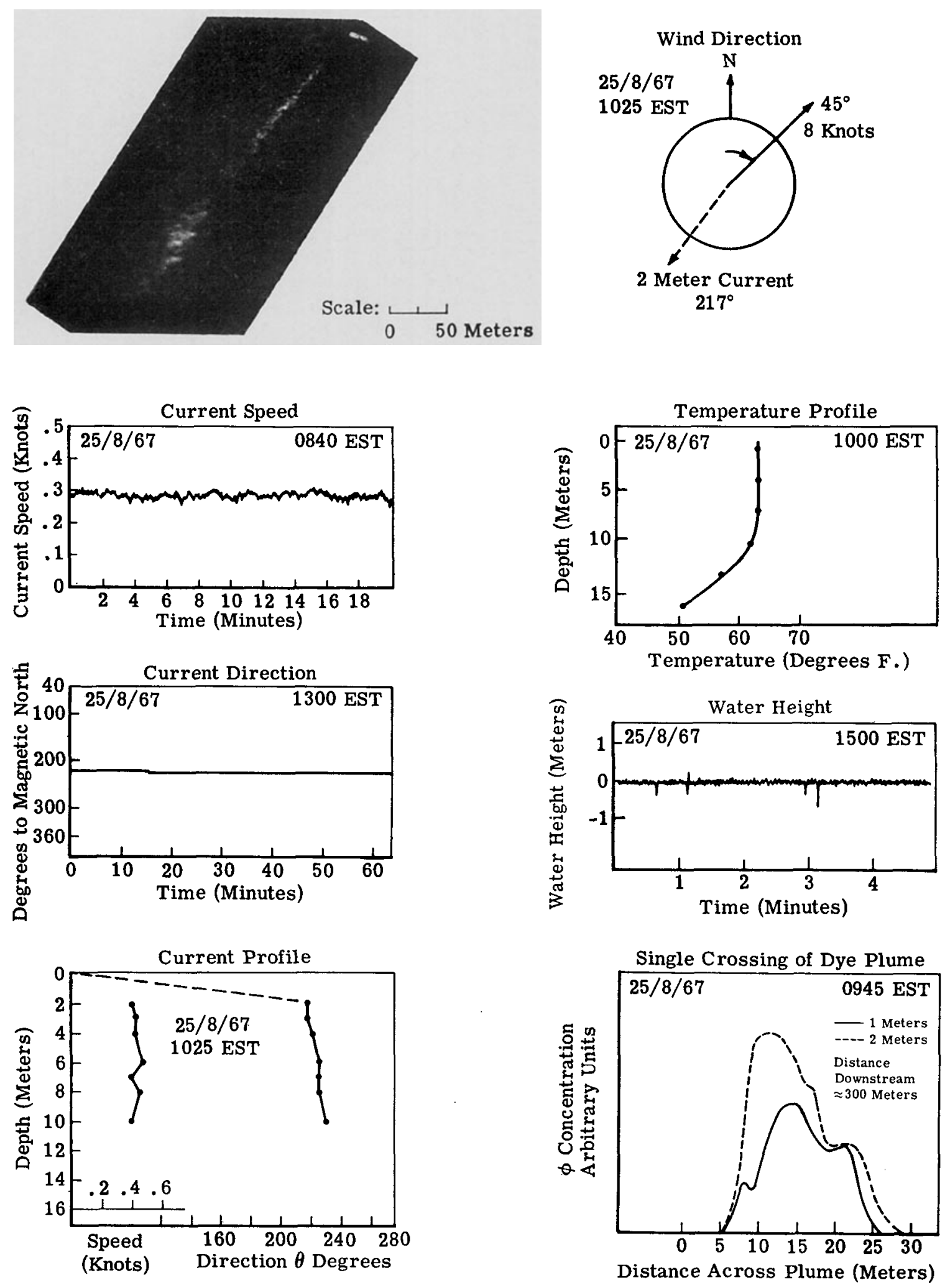

FIG. 6. Collected data for diffusion experiment on 25 September 1967. 
equally spaced across the plume and then punched on IBM computer cards. The fluorometer output can be considered proportional to the concentration of the dye, $q_{i}\left(y_{i}\right)$, at a given location $y_{i}$. The concentration profile between two flags placed on each side of the dye plume was first integrated to give the total amount of marked fluid, i.e.,

$$
Q=\sum_{i} q_{i}
$$

The center of mass of the concentration profile has the position

$$
y_{c}=\frac{1}{Q} \sum q_{i} y_{i}
$$

where $y_{i}$ is the distance of the concentration $q_{i}$ from one marker flag. The variance $\sigma^{2}$ about the mean of the concentration profile is

$$
\sigma^{2}=\frac{1}{Q} \sum q_{i} y_{i}{ }^{2}-y_{c}{ }^{2} .
$$

The variance $\sigma^{2}$ of each ( $j$ th) crossing was used to calculate the average standard deviation of the plume. Since each crossing was given equal weight (assumed to have an equal value of $Q$ ), the mean standard deviation for $n$ crossings ( $n$ was about 15 ) was determined by

$$
\sigma_{y}^{2}=\frac{1}{n} \sum_{j=1}^{n} \sigma_{j}^{2}
$$

The quantity $\sigma_{y}$ at a depth of $2 \mathrm{~m}$ has been plotted in Fig. 7 with respect to distance downstream for each experiment. Also shown in this figure (full curve) is the standard deviation of the plume calculated from the "typical" lateral diffusivity given by Csanady (1964) for "regular" diffusion. The two cross sections observed
Tahle 1. Plume and current statistics.

\begin{tabular}{cccccrccc}
\hline \hline $\begin{array}{c}\text { Experi- } \\
\text { ment } \\
\text { no. }\end{array}$ & $\begin{array}{c}\text { Date } \\
(1967)\end{array}$ & $\begin{array}{c}U \\
(\mathrm{~cm} \\
\left.\mathrm{sec}^{-1}\right)\end{array}$ & $\begin{array}{c}x \\
(\mathrm{~m})\end{array}$ & $\begin{array}{c}\sigma_{y} \\
\left(\mathrm{~m}^{2}\right)\end{array}$ & $\begin{array}{c}K_{\nu} \\
\left(\mathrm{cm}^{2}\right. \\
\left.\sec ^{-1}\right)\end{array}$ & $\begin{array}{c}\text { Time } \\
\left(\overline{u_{2}^{2}}\right)^{\frac{1}{2}} / U\end{array}$ & $\begin{array}{c}\text { scale } \\
(\mathrm{min})\end{array}$ \\
\hline 1 & 23 Sept. & 25 & 285 & 6.4 & 180 & 0.02 & 28 \\
2 & 24 Sept. & 25 & 285 & 4.06 & 72 & 0.011 & 28 \\
& & & 735 & 7.6 & 98 & & \\
3 & 25 Sept. & 15 & 285 & $\begin{array}{c}7.0 \\
137\end{array}$ & 0.001 & 28 \\
& & 810 & 44 & 1500 & & \\
\hline
\end{tabular}

on 25 August clearly show "accelerated" diffusion, while the results of 24 August (and of 23 August, as far as may be judged from the data) appear to characterize "regular" diffusion, i.e., diffusion dominated by horizontal turbulent fluctuations in the current.

Table 1 shows the observed results relevant to the growth rates of the plumes. The apparent eddy diffusivities were calculated from

$$
K_{y}=\frac{U \sigma_{y}^{2}}{2 x}
$$

where $U$ is mean current speed and $x$ distance from the source. The velocity fluctuations, $u_{2}$, normal to the mean velocity, were recorded $2 \mathrm{~m}$ below the lake surface while the experiment was in progress; the lateral turbulent intensity, $\left(\overline{u_{2}^{2}}\right)^{\frac{1}{2}} / U$, is given in Table 1. A lower frequency limit for the fluctuations must be chosen in order to obtain a statistic that is indicative of the lateral velocities which contribute to relative diffusion. The figures in Table 1 refer to energy above 0.066 cycle $\mathrm{min}^{-1}$. The Eulerian "time scales" in Table 1 were also calculated from the lateral current records. The problems which arise when such a statistic is estimated from records that are short compared with the characteristic time of the turbulence are discussed by Jones and Kenney (1971). The turbulence intensities

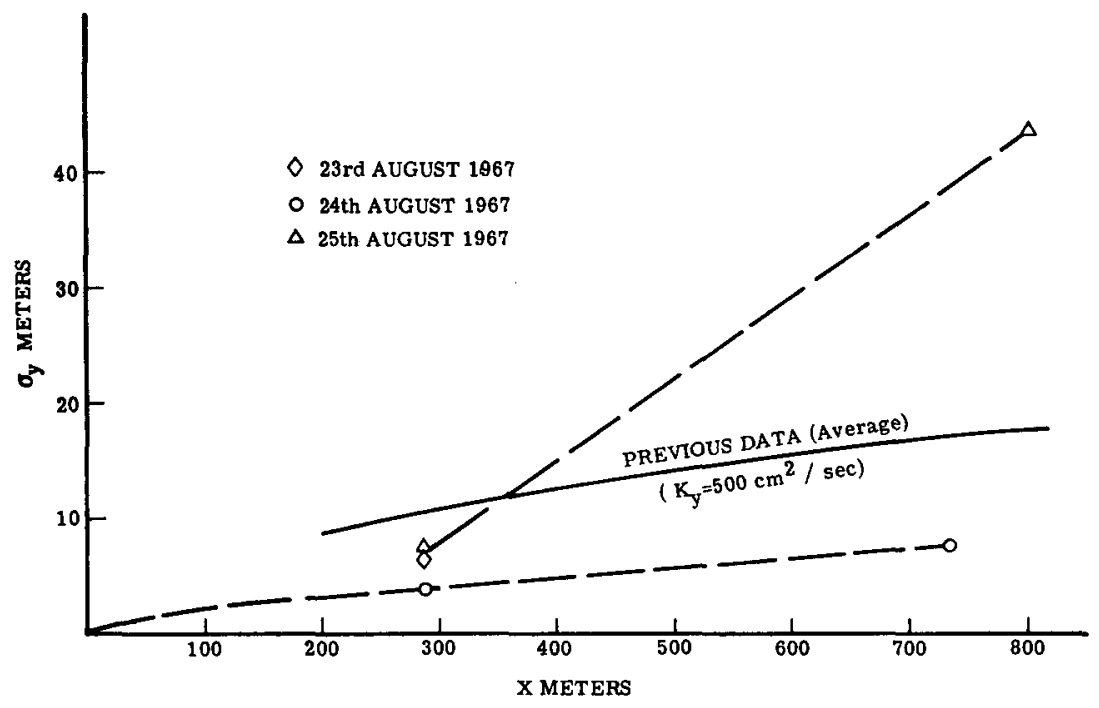

FIG. 7. Standard deviation of relative diffusion as a function of distance downstream. 
listed in Table 1 are low in comparison with what one may judge to be an "average" level of 0.05 proposed in the above paper.

\section{Discussion}

Accelerated diffusion requires two conditions, variation of mean velocity direction with depth, and good vertical diffusion, to ensure that marked particles are carried into regions of fluid moving in different directions. Of the three experiments in question only that on the 24th has significant measured skewness at the source depth of $2 \mathrm{~m}$. However, the gross plume characteristics on the 25th indicate that the current above $2 \mathrm{~m}$ was significantly skewed, i.e., the variation in direction of the two segments began very close to the source. This conclusion also follows if one assumes that the surface current is approximately aligned with the wind, which, on this day, diverged $172^{\circ}$ from the $2 \mathrm{~m}$ current. It was shown in Jones (1968) that a change in wind direction took an average of $18 \mathrm{hr}$ to penetrate to $2 \mathrm{~m}$. However, the rate of penetration is thought to be strongly dependent on the magnitude of direction change and the wind speed. Since the wind diverged only $50^{\circ}$ from the $2 \mathrm{~m}$ current on the $23 \mathrm{rd}$ and the plume was not observed to be segmented, the directional skewness must be restricted to the near surface. Estimations of the current direction profiles are shown dotted in Figs. 4-6.

A good indicator of vertical diffusion which may be inferred from aerial photographs is the length of the plume. All "regular" dye plumes observed have lateral diffusivities of much the same order of magnitude. Since striated plumes are typically an order of magnitude shorter than laminar-like ones, the vertical diffusivity must be much larger on these days. It is an attractive proposition to consider that the same mechanism which produces the striation also causes increased vertical diffusion. The current records on the 23rd have a quasiperiodic trend with a period of about $1 \mathrm{~min}$. When multiplied by the mean current speed this produces a wavelength which corresponds approximately to the spacing of the striations in the dye plume. This leads one to speculate that the striations are caused by a quasi-periodic current structure. Since only the current speed record has this type of periodicity on the 25th (the direction record shows no fluctuations), this would be consistent with a structure with its axis perpendicular to the mean current on this day (just as the striations are at this depth). A structure which involves only periodic horizontal fluctuations perpendicular to a line or a series of parallel lines must have corresponding vertical fluctuations to satisfy continuity. This would account for the increase in vertical diffusivity.

These striations come and go rather rapidly as is well illustrated by the plume of 9 September 1966 in Kenney (1967). The current records show no predomi-
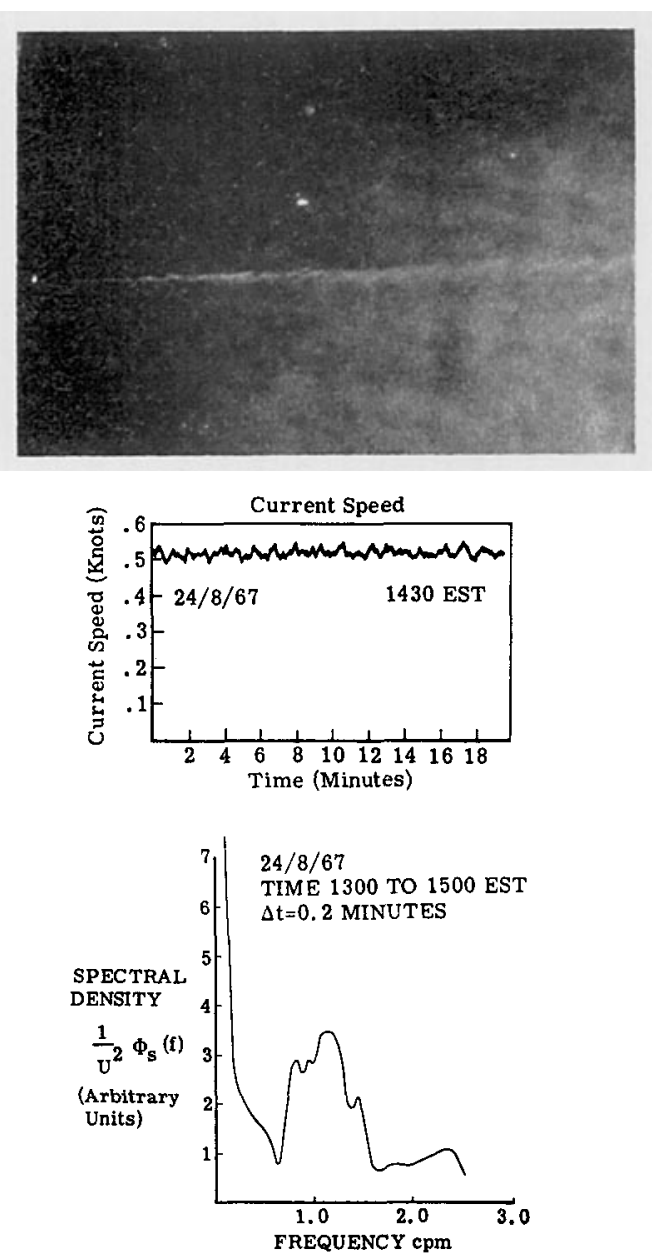

Fic. 8. Photograph of dye plume at 1415 EST 24 September 1967 together with the current record and its power spectral density $\phi_{s}$.

nant periodicity on the 24 th at 1100 EST nor is the plume striated, but later in the day, at 1430 , strong periodicity was observed in the current record (Fig. 8). This manifests itself as a peak in the spectra, reproduced in Fig. 8 from Jones and Kenney (1971). The plume at 1415 had taken on a striated characteristic not apparent in the earlier photograph used in Fig. 5. Since the striations are aligned with the wind direction both in the 1966 and 1967 experiments, the wind must play an important part in their formation. Consequently, we postulate that the wind plays a central role in diffusion in the top few meters of the lake, first, by being responsible for much of the current direction changes with depth, and second, by being an essential ingredient in the generation of the "quasi-periodic" structures which can lead to large vertical diffusion and accelerated horizontal diffusion.

Of the three experiments only that of the 25 th meets the requirements for "accelerated" diffusion. The other 
two experiments have horizontal lateral diffusivities (shown in Table 1) that are significantly lower than the "average" of $500 \mathrm{~cm}^{2} \mathrm{sec}^{-1}$ quoted by Csanady (1964). The lateral turbulence intensity was also lower than the average of 0.05 proposed in Jones and Kenney (1971). Furthermore, if we assume that the vertical diffusion was negligible on the 24 th, then the horizontal lateral diffusivities of the two "regular diffusion experiments" follow the trend of increasing diffusivity with increasing lateral turbulence. Thus, the turbulence level is a very important factor in determining the day-to-day variation in the rate of "regular" diffusion.

\section{Conclusions}

The striations observed in two of the dye plumes were of the same wavelength as quasi-periodic structures observed in the simultaneous current speed records. These striations are accompanied by good vertical mixing and also by accelerated diffusion, if there is a significant mean current direction change with depth. Since both the striations and the current shear appear to be strongly influenced by the wind, it is postulated that the wind plays a central role in diffusion in the top few meters of the lake.
Acknowledgments. This work was financially supported by the National Research Council under Grant A-1317 to Dr. G. T. Csanady.

\section{REFERENCES}

Csanady, G. T., 1963: Turbulent diffusion in Lake Huron. $J$. Fluid Mech., 17, 360-384.

- 1964: Turbulence and diffusion in the Great Lakes. Publ. No. 11, Great Lakes Research Div., University of Michigan, Ann Arbor.

- - 1966: Accelerated diffusion in the skewed shear flows of lake currents. J. Geophys. Res., 71, 411-420.

Icheye, T., 1967: Upper ocean boundary-layer flow determined by dye diffusion. Phys. Fluids, 11, S270-277.

Jones, Ian S. F., 1968: Surface layer currents in Lake Huron. Proc. 11th Conf. Great Lakes Research, Intern. Assoc. Great Lakes Res., University of Michigan, Ann Arbor, 406-411.

- , and Kenney, B. C., 1971: Turbulence in Lake Huron. Water Res. (in press).

Kenney, B. C., 1967: Dye plume meandering. Proc. 10th Conf. Greal Lakes Research, Intern. Assoc. Great Lakes Res., University of Michigan, Ann Arbor, 277-288.

Pritchard, D. W., B. Okubo and H. H. Carter, 1966: Observations and theory of eddy movement and diffusion of an introduced tracer material in the surface layers of the sea. Proc. Symp. Disposal Radioactive Wastes into Seas, Oceans and Surface Waters, Intern. Atomic Energy Agency, Vienna, $397-424$. 